\title{
Experimentall study: A comparison of analgesic effect in a rat model of acute pain treated with either paracetamol or morphine.
}

\section{Roumelioti Charikleia, ${ }^{1}$ Panagopoulos Nikolaos, ${ }^{2}$ Pagkalidou Eirini, ${ }^{3}$ Damigos Dimitrios ${ }^{1}$ \\ 1University of loannina \\ 2. Anesthesiologist \\ 3. Msc Biostatistics}

1BACKGROUND AND GOAL OF STUDY: Pain may have somatic and behavior effects. Antinociceptive action may be promoted with analgesics, acting centrally and peripherally. This experimental animal study was conducted to compare the analgesic activity of morphine versus paracetamol in the hotplate test in animal model with rats.

MATERIAL AND METHOD: Morphine is an opioid analgesic with central and peripheral action. Paracetamol's mechanism of action is still unknown. Twenty- four male Winster mice were divided in three groups, the first group $(n=8)$ was the control ( $2 \mathrm{ml}$ normal saline was injected intraperitoneally), the second group $(n=8)$ was the morphine $(10 \mathrm{mg} / \mathrm{kg}$ of morphine was injected intraperitoneally) and the third group $(n=8)$ of paracetamol $(200 \mathrm{mg} / \mathrm{kg}$ of paracetamol was injected intraperitoneally). At 30 minutes interval and 60 minutes interval after the administration of the drugs, the animals were put on Hot-plate. Paw-lick test or bounce were used to determine pain threshold. Measurement were made at 30 minutes and at 60 minutes after the administration of the drug. All the animals were sacrificed after the experiment.

RESULTS AND DISCUSSION: Morphine antinociceptive action did not have statistical significant difference with that of paracetamol at 60 minutes ( $P$ 0.927>0.05) but it had increased pain threshold at 30 minutes $(P$ 0.021<0.05). Morphine had statistical significant antinociceptive action at 30 ( $P$ $0.003<0.05)$ and $60(P 0.009<0.05)$ minutes. Paracetamol had statistical significant antinocipeptive difference in $60(P 0.011<0.05)$ minutes but not at $30(P 0.316>0.05)$ minutes. Median of difference of measurements for paracetamol time $30 \mathrm{~min}$ and time $60 \mathrm{~min}$ was significant different $(P=0.027<0.05)$. Paracetamol displayed an antinociceptive activity as efficacious as morphine at dose $200 \mathrm{mg} / \mathrm{kg}$, comparable with that of $10 \mathrm{mg} / \mathrm{kg}$ morphine at 60 minutes.

CONCLUSIONS: According to our results, paracetamol may be an alternative analgesic

ACKOWLEDGEMENTS: I would like to thank Professor of Pharmacology, in University of Ioannina, Marselos Marios, who supported me in this study. 